\title{
Response mode and speed of access to different types of information in memory
}

\author{
JOHN H. MUELLER and MICHAEL R. COURTOIS \\ University of Missouri, Columbia, Missouri 65211
}

\begin{abstract}
Over three tasks, subjects decided whether members of word pairs were spelled alike, were pronounced the same, or represented the same taxonomic category. Subjects in different response mode conditions indicated their decisions by (1) responding "same" or "different" for each pair, (2) responding only when the pair called for a "different" response (skipping same pairs), or (3) responding only when the pair required a "same" decision (skipping different). Physical identity decisions were faster than homophone decisions, and category decisions were slower than homophone decisions. Response mode was not significant as a main effect, nor did it interact with type of decision.
\end{abstract}

The focus of this report is a methodological question in a reaction time procedure in which subjects must decide whether the members of word pairs are the same or different on some basis. For example, it has been found that reaction time is slower for a decision about category membership than for physical identity (spelling), with homophone decisions yielding intermediate reaction times. Furthermore, these access times have been shown to vary as a function of arousal (Schwartz, 1979) and verbal ability (Goldberg, Schwartz, \& Stewart, 1977).

The present experiment concerned the effect of response mode on access time for these three types of information as a function of the manner in which subjects indicate their decisions. Subjects are typically required to respond one way or the other for each pair, a procedure that will be designated the "both" condition. In this case, subjects must make the task-defined decision and then make an output decision as well (Pachella, 1974). That is, (1) is the pair the same or different; then (2) given it is the same (different), which key do I press? However, an alternative procedure can be used, and it derives from procedures used by Egeth (e.g., Egeth, Marcus, \& Bevan, 1972). In this case, subjects respond only if the members of the pair are the same (different) on the dimension in question, but they withhold a response if the members of the pair are different (the same). These single-response conditions will be referred to as "same only" and "different only." The single-response procedure lessens the requirement of deciding on the appropriate response to make. The response-decision component in the both condition may only be a constant, adding equally to access time for all

Requests for reprints should be sent to John Mueller, Psychology Department, 210 McAlester Hall, University of Missouri, Columbia, Missouri 65211. The authors would like to acknowledge Ronald Goldberg and Kenny Spencer for their assistance. This research was supported in part by funds from the Research Council of the Graduate School of the University of Missouri. three types of decisions; however, it is possible that it is a greater factor for one type of decision than for another. This experiment was conducted simply to explore this possibility prior to conducting other research within this framework.

\section{METHOD}

\section{Subjects}

Twenty-four subjects were divided into three groups defined in terms of how the response was indicated. Men and women were randomly distributed in the three groups, and all received course credit in introductory psychology for participating.

\section{Materials}

There were three sets of 60 word pairs each. In Set $\mathrm{P}, 30$ pairs were physically identical and 30 were not. In Set $H, 30$ pairs were homophones (e.g., DEER-DEAR), and 30 were not. Set $C$ had 30 pairs that were instances of the same taxonomic category (e.g., DEER-ELK), and 30 were not. The pairs were adapted from those used by Goldberg et al. (1977) and Schwartz (1979); a further description of the items may be found in those reports. The 60 pairs in each set were shown to the subject four times, in different orders, with the order differing for each subject. The first block of 60 was considered practice and was discarded from the analysis.

\section{Procedure}

The words were presented simultaneously on a CRT controlled by a PDP-11/34 computer. For each pair, subjects in the both condition responded by pressing one of two keys, indicating same or different according to the required decision (spelled same, homophones, category membership). Subjects in the same-only condition were instructed to respond only when the pair members were the same but not to respond when the pair members were different. In this case, the pair was automatically replaced at the end of $2 \mathrm{sec}$, without the subject making any response. The procedure in the different-only condition merely reversed that in the same-only group. All subjects had Sets $\mathrm{P}, \mathrm{H}$, and $\mathrm{C}$, but in different order, with a task break of about $3 \mathrm{~min}$ between sets.

\section{RESULTS AND DISCUSSION}

Table 1 presents the mean reaction times for each type of decision. In each case, only correct responses 
Table 1

Average Reaction Times (in Milliseconds) by Stimulus Set for Each Response Mode

\begin{tabular}{lcrrc}
\hline & \multicolumn{4}{c}{ Stimulus Set } \\
\cline { 2 - 5 } & Spelling & Homonym & Category & All \\
\hline Both Same & 853.2 & 872.3 & 982.5 & 902.7 \\
Same Only & 690.5 & 808.6 & 862.9 & 787.3 \\
All Same Pairs & 771.9 & 840.5 & 922.7 & 845.1 \\
Both Different & 844.8 & 1027.5 & 1056.1 & 976.1 \\
Different Only & 695.3 & 865.6 & 973.3 & 844.8 \\
All Different Pairs & 770.1 & 946.5 & 1014.7 & 910.4 \\
\hline
\end{tabular}

were included. The average reaction time for each of the last three blocks of 60 pairs constituted the data of primary interest. For purposes of analysis, the times of the "same" pairs in the both condition were used for comparision to the same-only group, using a 2 (response mode) by 3 (stimulus set) by 3 (block) mixed factorial analysis of variance, with the last two factors serving as repeated-measures factors. An analogous analysis was performed using the "different" pairs from the both condition to compare with the different-only condition. Finally, the same-only and different-only pairs were compared in the same design. Similar analyses of the standard deviations of the reaction times within each block were performed, but there were no significant effects, so those data will not be considered further. Effects described as significant involve $p<.05$ or better, unless noted otherwise.

\section{Same Pairs}

The response mode main effect was not significant $[F(1,14)=2.22, \quad M S e=215,292]$, nor did response mode interact with stimulus set $[\mathrm{F}(2,28)=1.85$, MSe $=$ $15,942]$. The stimulus set main effect indicated that category decisions were slower than homophone decisions, and the latter were also slower than spelling decisions (means $=922.7,840.5,771.9$, respectively). The blocks main effect $[\mathrm{F}(2,28)=5.13$, MSe $=6,834]$ indicated significant reductions in speed from Block 2 to Block 3, with no further change to Block 4, but there were no significant interactions with block $(\mathrm{Fs}<1.53)$.

\section{Different Pairs}

The only significant effect was the stimulus set main effect $\quad[F(2,28)=23.53, \quad M S e=32,514]$. Category decisions were significantly slower than homophone decisions, which in turn were significantly slower than spelling decisions (means $=1,014.7$, 946.5, 770.1, respectively). The response mode main effect was not significant $[\mathrm{F}(1,14)=2.05, \mathrm{MSe}=302,436]$, nor was the Stimulus Set by Response Mode interaction $(\mathrm{F}<1)$. While subjects improved somewhat between Blocks 2 and 3 , the difference was not significant $[F(2,28)=$ 2.94, $\mathrm{MSe}=15,654, \mathrm{p}<.07]$, nor were there any interactions with block $(\mathrm{F}<1)$.

\section{Same-Only vs. Different-Only}

The stimulus set main effect was the only significant result $\quad[F(1,14)=27.89, \quad \mathrm{MSe}=22,389] ; \quad$ spelling decisions were faster than homophones, which were in turn faster than category decisions. Neither the response mode nor blocks main effects was significant (Fs $<1.86)$, and there were no interactions (Fs $<1.50$ ).

The results of this experiment seem to establish that the findings for stimulus set are not affected by the response requirements of the task. In each output condition, the expected pattern was obtained, with physical identity decisions faster than acoustic similarity decisions and acoustic decisions faster than category membership decisions. This was true for both "same" and "different" pairs and for all response modes. The same-only and different-only response modes were generally faster than the both response mode, but not significantly so, and there were no Stimulus Set by Response Mode interactions.

\section{REFERENCES}

Egeth, H., Marcus, N., \& Bevan, W. Target-set and responseset interactions: Implications for models of human information processing. Science, 1972, 176, 1447-1448.

Goldberg, R. A., Schwartz, S., \& Stewart, M. Individual differences in cognitive processes. Journal of Educational Psychology, 1977, 69, 9-14.

PACHELla, R. G. The interpretation of reaction time in informationprocessing research. In B. H. Kantowitz (Ed.), Human information processing. Hillsdale, N.J: Erlbaum, 1974.

Schwartz, S. Differential effects of personality on access to various long-term memory codes. Journal of Research in Personality, 1979, 13, 396-403.

(Received for publication November 19, 1979.) 